\title{
Estados nacionales y derechos humanos en la era de la globalización *
}

\author{
OTFRIED HÖFFE \\ Universidad de Tubinga
}

El Estado nacional, modelo paradigmático de configuración política durante la modernidad, se encuentra hoy profundamente cuestionado por la presión que sobre él ejerce tanto las tendencias hacia la globalización de las relaciones econó- micas como por la aspiración universalista de los derechos humanos, fundamento de su propia legitimidad. Por ello ha de ir abriéndose paso el "Estado nacional ilustrado", el cual se caracteriza por experimentar seis procesos de modernización.

\section{Los Estados nacionales bajo la presión de tener que justificarse}

La política no ha resuelto todavía la principal tarea de los últimos años: ¿cómo puede vincularse el fenómeno - relativamente- nuevo de la globalización con la conquista política de la modernidad, con la democracia comprometida con los derechos humanos? Hasta ahora su modelo consistía en el Estado soberano particular, conocido a menudo como Estado nacional. Según parece, desde hace algún tiempo éste se bate con la espalda contra la pared. Al menos dos flancos se muestran sometidos a la presión de tener que justificarse. En la praxis política, el Estado nacional se ve asediado tanto por la globalización como por su contrapunto, la regionalización, y ocasionalmente - dentro del ámbito de la teoría política- por principios universalistas como los derechos humanos que presuntamente no se avienen conla particularidad de los distintos Estados. A pesar de ello, el Estado "nacional" particular más o menos homogéneo en aspectos políticamente importantes sigue siendo un modelo de ordenamiento político. Así y todo, no debe contemplarse desde la exclusiva posición de Europa. Junto a la unión entre nación y Estado territorial realizada paradigmáticamente por Francia se encuentran desarrollos comparables en otros lugares, como por ejemplo China, Corea y Japón. Cuando no se equipara la nàción con la escalada del nacionalismo, entonces se sigue la comprensión neutral inglesa o francesa y se asume el modelo de una valoración con la que no puede competir ningún otro modelo. Al Estado nacional democrático o a la democracia "nacional" le corresponde una preeminencia normativa. Aún

* Versión castellana de Roberto R. Aramayo y Juan Carlos Velasco. 
cuando se abren paso otros modelos, todavía ninguno ha logrado reemplazarle: ni un ordenamiento preestatal, exclusivamente social, ni un ordenamiento supraestatal, ni tampoco la creciente red de organizaciones intra- y supranacionales. Por el contrario, existen dificultades para presentar una alternativa válida al modelo, esto es, al Estado constitucional democrático.

En vista de este relativamente complejo diagnóstico -presión para justificarse y preeminencia- podrían considerarse las comunidades políticas como entidades nada prestas al aprendizaje, ya que no se doblegan a la presión de tener que justificarse y persisten en su estatalidad nacional. Pero quizás exista también un engaño de perspectiva, pues este diagnóstico sobrevalora la fuerza de la presión existente sobre el Estado a tener que justificarse, pero infravalora su derecho a permanecer. Lo siguiente, sin embargo, apenas resulta discutible: la progresiva globalización genera una necesidad de actuar que los Estados particulares por sí solos no pueden llevar a cabo. Y dado que una parte de la necesidad de actuación global ya se cubre globalmente, la erosión de los Estados particulares ha comenzado hace ya tiempo. Ciertamente no debe sucumbirse al sofisma economicista de que la globalización sólo tiene lugar en los mercados económicos y financieros. Incluso la globalización económica sirve de base tanto a decisiones políticas -recuérdese el sistema de Bretton Woods, el GATT y la OCDE- como a innovaciones técnicas, en parte de índole militar y en parte no. Además a la globalización de la economía y del mercado de trabajo y a su contrapartida, el turismo global, se le añade una variopinta plétora de fenómenos poco o apenas económicos, cuyo conjunto, incluida la globalización económica, genera una comunidad mundial en tres dimensiones:

La primera dimensión, una heteróclita "comunidad de la violencia", se muestra en las guerras que mediante el desarrollo armamentístico amenazan con adoptar una escala global, así como en la criminalidad organizada y los daños medioambientales que sobrepasan las fronteras. También tiene una faceta anamnética. Una "memoria crítica mundial" retiene en el recuerdo los grandes actos de violencia y atiende la justicia mediante el recuerdo. Pues sólo una memoria mundial que no conserve selectivamente los crímenes alevosos como lo hacia hasta ahora (manteniendo presente la reparación en algunos lugares, mientras que en otros resulta inexistente), esto es, tan sólo una justa memoria mundial contribuye a prevenir futuros actos violentos.

Afortunadamente la amplia comunidad de la violencia se completa con una amplia «comunidad de cooperación». Incluso en ella, economía y finanzas, : mercado de trabajo, medios de transporte y comunicación, así como el turismo, juegan un papel, aunque no único. «Se globaliza» también la filosofía y las ciencias, además de la medicina y la técnica, los sistemas escolares y universitarios, la cultura juvenil, y no en último lugar una considerable parte de los mass media, del cine, el teatro, la arquitectura y la música. Del Estado de derecho liberal procede también una presión a tener que justificarse, pues 
las violaciones de derechos humanos son recriminadas mundialmente, aunque todavía no de modo efectivo. Estas violaciones chocan contra una protesta mundial a la que pertenecen los elementos a partir de los cuales crece una esfera pública general global, una esfera pública mundial. Ésta se fortalece mediante el derecho internacional y las organizaciones gubernamentales y no gubernamentales globalmente competentes.

No solamente en la economía, sino también en todos estos ámbitos predomina la competencia. Con buenas razones se espera de ello una riqueza colectiva que se despliegue en el ámbito económico, científico y cultural. La competencia tiene empero también cargas adicionales internas a la economía, como sería el desempleo, y otras externas a la economía, como serían los costes medioambientales. En ellos y en las víctimas de la violencia internacional se manifiesta la tercera dimensión de la comunidad mundial. Es la comunidad de destino en sentido estricto. Ésta, la "comunidad de necesidad y sufrimiento", se ve desafiada por las catástrofes naturales, el hambre y la pobreza, además de por los grandes movimientos migratorios y de refugiados, y no en último lugar por el subdesarrollo económico, pero también político y cultural.

Obviamente, las tres dimensiones proclaman una necesidad de actuar globalmente que relativiza la posición del Estado particular, aun cuando en algún respecto éste se mantiene como modelo. Del mismo modo que una sociedad particular doblega las fuerzas (económicas y culturales) del mercado en el marco de la democracia y los derechos humanos, así también la necesidad de actuar globalmente exige una democracia global. Con ella, en modo alguno, se asigna un derecho exclusivo a la estatalidad ni tampoco se le niega toda capacidad de dirección a las formas alternativas de gobierno. Pero debe recordarse que el proyecto político de la modernidad, el Estado democrático de derecho, representa una conquista de rango moral que no puede ser sacrificada en aras de los mercados económicos y financieros globales. La respuesta en ningún caso suficiente, pero normativamente irrenunciable, a la globalización se llama democracia mundial.

Este imperativo de democracia mundial se opone a una segunda suerte de economicismo: a la eliminación de la política que llevan a cabo el mercado y los dirigentes del mercado activos a lo largo y ancho del mundo. En ocasiones incluso predomina un fatalismo que considera inevitable dicha eliminación. En realidad no existe ningún destino anónimo; la globalización tiene nombres tales como los acuerdos sobre la liberalización del mercado mundial. Y del mismo modo como el mercado intraestatal está sometido a las condiciones marco, no cabe excluir a priori un marco análogo para el mercado global. A lo sumo es la política misma la que se subordina a las fuerzas del mercado, o sino se somete a los criterios sociales ecológicos mínimos y al principio de la democracia. Sin duda una prudente sociedad mundial se abandona a muchas cosas: a la creatividad de los individuos y grupos, a la libre competencia y también a la evolución social. Pero precisamente porque su capacidad creadora 
se ve reclamada en otros lugares, se requiere también su forma habitual de organización, la democracia comprometida con el derecho y la justicia.

Aunque la globalización demande una democracia global, sería precipitado declarar el Estado particular o el Estado nacional como fórmula superada. Pues aunque sea sólo a causa de las significativas prestaciones que desempeña, podría elevarse, a pesar de alguna nefasta perversión, por encima del modelo mundialmente dominante. Por ejemplo, separa el Estado y la sociedad, de donde se sigue la libertad religiosa, económica y cultural de los individuos. La libertad económica contribuye además al bienestar material. De otro lado, ni la economía moderna, ni la administración moderna resultan pensables sin aquella forma de integración comunicativa de la población que sólo ha logrado el Estado nacional. También la renovación de la educación y la ciencia europeas, así como la introducción de la escolaridad obligatoria de manera generalizada y la elevación del nivel de educación y formación de todos los ciudadanos son prestaciones civilizatorias con raíces propias en el Estado nacional. Además de todo esto, el Estado nacional asume la responsabilidad de las costes adicionales del desarrollo económico. Esto va perfeccionando la comunidad de solidaridad; en ella los antiguos súbditos se convierten en ciudadanos en un sentido enfático: socios jurídicos que se sienten responsables unos de otros.

\section{Estado nacional y derechos humanos}

Además el Estado nacional proporciona a la ética universalista del derecho y del Estado una primera realidad. Esto da cabida a la idea de los derechos humanos y fundamentales, conduce a la soberanía popular y al parlamento general y suprime la servidumbre, los privilegios estamentales y también la desigualdad jurídica de la mujer. Sin embargo, la violencia que acompaña el surgimiento de los Estados nacionales no puede quedar ocultada, ni la xenofobia ni ese recrudecimiento suyo que da pie a la guerra, ni tampoco el imperialismo ni esa limpieza lingüística que en algunos lugares incluso resulta ser étnica. Pero, por el lado positivo, el Estado nacional da lugar a la democracia cualificada. Y las sociedades sin democracia apenas pueden llegar a establecerse si no se llevan a cabo las mencionadas prestaciones, lo que se ve facilitado por un "mundo de la vida nacional" y compartido.

La filosofía del Estado puede situarse en la estela de Hegel y en el suelo de las naciones puede verse surgir el Estado de derecho. No se comprende, . de todas formas, por qué el principio conductor de la filosofía del derecho hegeliana, la libertad como derecho, debe restringirse a la perspectiva interna de la nación, en vez de ampliarse -con Kant- a la perspectiva externa, esto es, al derecho de gentes y al derecho cosmopolita. Pues en vista de la necesidad de actuar globalmente y de los principios universalistas del derecho y del Estado no hay Estado nacionalista y menos aún Estado agresivo que no sea cuestionado. 
La única forma hoy en día legítima y con futuro es el "Estado nacional ilustrado", el cual, tal como se tratará más adelante, se distingue por seis modernizaciones.

\section{Una legitimación globalizadora de los derechos humanos}

Desde su origen la filosofía está sujeta a una pretensión de universalidad: para los problemas generales, a menudo universales, busca mediante argumentos válidos universalmente enunciados que sean asimismo válidos universalmente. A la vista de la correspondiente duda -que en realidad los principios universales tan sólo sean válidos de forma particular- la filosofía se lanza a un debate globalizador, a un discurso en parte intercultural, en parte transcultural (cfr. Höffe, 1996, cap. 1; y también Höffe, 1999 y 1999a). En relación al derecho y al Estado este discurso conduce a tres niveles:

En la teoría del derecho y del Estado este discurso no apela a los elementos específicos de la cultura política europeo-americana, ni con respecto a los principios normativos ni en referencia a las circunstancias empíricas. Pues sólo alli donde por de pronto se pasa por alto todas las peculiaridades, las sociedades, que son básicamente heterogéneas, pueden comprometerse a pesar de ello con el bien común. El precio a pagar resulta evidente: no se obtiene ningún ordenamiento jurídico nítidamente perfilado, sólo principios formales. Pero en realidad esto no representa ningún precio, sino una ventaja. Los principios son válidos sin alternativas $y$, a pesar de las concretas configuraciones, permanecen abiertos a la experiencia, a la prudencia y a las diferentes condiciones marginales, incluyendo las tradiciones y modelos sociales.

En el segundo nivel, el de la historia del derecho y del Estado, el discurso intercultural pone en relación la conciencia histórica con los conocimientos de historia social. Recuerda, por ejemplo, que la civilización occidental está impregnada ya en su comienzo de fuentes extraoccidentales, como es el caso de la cultura griega, que presenta influencias orientales (egipcias, babilónicas, hititas, fenicias, etc.), y que la transmisión de esta cultura en la Edad Media sólo se logró en parte por mediación de Roma, pero en una parte no insignificante por medio de los cristianos sirios y del espacio cultural arábigo-musulmán. El discurso, por de pronto, no olvida a "los occidentales" todas aquellas patologías como el colonialismo, la intolerancia religiosa y el Estado absolutista, contra las que los derechos humanos resultan necesarios como terapia. De todos modos, sabe también que ni la colonización ni el imperialismo fueron inventados por la modernidad europea. Fueron ya puestos en práctica por los egipcios, los fenicios y los persas, más tarde por Grecia y Roma, además de por los incas, en India y en China.

Debido a su conciencia histórica, el discurso intercultural encuentra precedentes en otras culturas para los tres componentes de la "comunidad moderna": la soberanía popular, los derechos humanos y la división de poderes. Para la soberanía popular se remite a las primitivas culturas de cazadores 
en las que las hordas constituidas parentalmente (clanes) toman en común sus decisiones (sobre la caza y su asentamiento). Carácter democrático tienen también muchas órdenes religiosas, como por ejemplo los dominicos y los franciscanos, cuyos superiores son elegidos por una asamblea de miembros, el capítulo, y además por un determinado tiempo. Y en la institución africana de las "pláticas" (palavers) se delibera entre los afectados tanto tiempo como sea necesario hasta que se consigue alcanzar un consenso. Además, a una gran parte de los derechos humanos los protege el derecho penal válido en el interior de los ordenamientos jurídicos (cfr. Höffe, 1999).

Tan importante o más resulta el tercer nivel: para la praxis del derecho y del Estado, el discurso intercultural aboga por una realización de los principios formales tan cautelosa que su franqueza lleva a ser realmente eficaz. Las pretensiones del derecho y la justicia de la civilización moderna tan sólo pueden ser exigidas a otras culturas si éstas mantienen un elevado grado de autonomía. En vez de tener que superar su identidad, tienen derecho a una aculturación: a una incorporación adecuada a su cultura.

Con el objeto de justificar los principios válidos que ahora empíricamente carecen de alternativa, la legitimación de los derechos humanos no parte de intereses habituales, pues en ellos predomina la diferencia. Se remite más bien a los intereses lógicamente superiores que mantienen relación con la conditio humana. Son intereses antropológicos, esto es, intereses de todo ser humano de cualquier cultura. $Y$ porque contienen las condiciones para poder tener y perseguir intereses en general, afectando así a la capacidad de actuar, poseen un rango (relativamente) trascendental.

Acerca de la determinación precisa en términos de contenido de los intereses tanto antropológicos como trascendentales existen controversias, aunque no afectan al fondo. Desde sus inicios griegos, la antropología filosófica sabe que la capacidad de actuar de los seres humanos se caracteriza por tres elementos: a) en contraposición a los puros seres racionales, a la divinidad o a un ángel, posee la capacidad de actuar de un zoon o animal: ser corporal y con vida; b) a diferencia de los animales corrientes se trata de un zoon logon echon o animal rationale, de un ser con capacidad de pensamiento y habla; c) y, no en último término, se trata de un zoon politikon, y en ello tanto en el sentido inespecífico del ens sociale, de la dependencia de la comunidad, como también en el sentido específico del ens politicum: la predisposición a una comunidad política, a una polis. En estas tres esferas existen intereses que son la condición de posibilidad de los intereses corrientes. Y en las tres esferas su realización depende de una reciprocidad, pars pro toto, de un intercambio. : Y dado que se refiere a intereses trascendentales es un intercambio trascendental. De él proceden los tres grupos de derechos humanos: derechos del ser vivo y corporal, derechos del ser que piensa y habla, así como los derechos del ser social y político.

Cuando se considera con más detenimiento, el intercambio trascendental tiene lugar de tres formas. Hay una reciprocidad negativa -el intercambio de 
renuncias- que conduce a los derechos de libertad negativa, existe también aquella reciprocidad positiva -el intercambio de prestaciones- que fundamenta los derechos de libertad positiva o derechos sociales y, finalmente, una reciprocidad de la autorización política que se condensa en los derechos de cogestión democrática.

Sin pretensión de exhaustividad, a continuación se enunciarán algunos derechos, cuyo carácter de derechos humanos difícilmente cabe poner en duda. Dado que bajo la apelación a los intereses trascendentales y a la vez antropológicos introducimos imágenes de lo humano culturalmente relativas, los correspondientes derechos cumplen sin problemas su pretensión de validez intercultural. Por lo demás, la afirmación contraria de una validez que sea meramente relativa en términos culturales tiene, por el contrario, sólo un significado político estratégico: gobiernos total o parcialmente totalitarios quieren protegerse de la crítica. Incluso cuando la aseveración contraria no está concebida estratégicamente, su fundamentación -llevada a cabo mediante la invocación de valores asiáticos o africanos presuntamente alternativos- puede invalidarse por regla general en términos culturalmente inmanentes.

\subsection{Integridad de cuerpo y vida.}

Comencemos con el intercambio negativo, esto es, con la reciprocidad de renuncias elementales.

La integridad de cuerpo y vida ofrece un claro ejemplo de un interés trascendental. Si bien cabe ofrecer la vida en calidad de mártires religiosos o políticos, o desistir de ella por el tedio de la vida, la vida no obstante posee un rango especial, ya que sin ella nada puede consumarse ni cumplirse su consumación. En este sentido, tanto el mártir como aquel que se suicida quieren decidir ellos mismos: el uno, para qué, el otro, cuándo terminar su vida $\mathrm{y}$, por regla general, también cómo terminar con ella; en cualquier caso, sencillamente habrán muerto.

Por dos condiciones empíricas generales, a todo hombre le amenaza el peligro de caer víctima de la violencia ajena; el peligro tiene una importancia antropológica: por una parte, no se puede evitar que a la larga se produzcan encuentros preñados de conflictos sobre la tierra limitada en términos espaciales y de recursos; por otro lado, en los eventuales conflictos los seres humanos pueden ser heridos por sus semejantes. En consecuencia, existe una igualdad elemental o reparto igualitario: los seres humanos son tanto posibles víctimas como posibles agentes de la violencia. No es algo, por ejemplo, vinculado a ciertas culturas, sino que el riesgo de la violencia constituye una parte de la conditio humana socialis y en principio no puede superarse en cualquier momento y lugar, tal como los teóricos sociales "utópicos" suponen.

En vista del riesgo general de violencia se plantea la cuestión de si uno más bien quiere preservar su completa libertad de acción y, en consecuencia, querer ser tanto víctima como agente de la violencia, o si se renuncia antes 
al derecho a la completa violencia (privada) para así no ser ni víctima ni agente. Según un primer principio de justicia, la igualdad, ha de responderse con una regla: o con una fórmula tanto-como o con una fórmula ni-lo-uno-ni-lo-otro.

Aunque la reciprocidad caracteriza a ambas opciones, a causa del interés trascendental por el cuerpo y la vida es preferible para todos la reciprocidad ni-lo-uno-ni-lo-otro que la reciprocidad tanto-como. Esto es, cualquier persona renuncia antes a la completa, "salvaje", libertad de acción para así poder mantener asegurada, por el contrario, una condición de la libertad de acción: cuerpo y vida. Aquí se muestra el intercambio trascendental como un intercambio trascendental de libertad: se restringe su libertad por mor de la libertad, y de la licencia ilimitada surge la libertad atada y asegurada; la "licentia" se transforma en "libertas".

Ni siquiera un interés irrenunciable fundamenta ciertamente una pretensión. Pues de acuerdo con la falacia relativa al tránsito del ser al deber ser o, lo que es lo mismo, visto desde una perspectiva puramente lógico-formal, de un interés no se deriva ningún derecho a su reconocimiento. El momento de legitimación que aún falta radica en la moral mínima de la reciprocidad. Se parte del hecho de que sólo allí donde existe el derecho subjetivo al cuerpo y a la vida los otros asumen la obligación de abstenerse de usar la violencia. Se insiste entonces de modo general en una pretensión a una prestación allí donde ésta de antemano se produce bajo la reserva de una contraprestación. Las pretensiones se justifican por una reciprocidad y las pretensiones universales por aquella reciprocidad universal que caracteriza al ser humano por el mero hecho de serlo. Allí donde puede realizarse un interés irrenunciable sólo en y a través de reciprocidad se transmite la irrenunciabilidad a la reciprocidad, y el correspondiente intercambio -en cuerpo y vida, el intercambio de renuncias a utilizar la violencia- es, por su parte, irrenunciable.

El correspondiente derecho humano existe no ya porque todo ser humano tiene un supremo interés en el cuerpo y la vida, sino sólo porque el interés únicamente puede realizarse en reciprocidad y porque además ya cada cual reivindica en el "sistema de reciprocidad" aquella prestación -la renuncia de los otros a la violencia- que sólo tiene lugar bajo la condición de la contraprestación, la renuncia propia a ejercer la violencia. Porque lo intercambiado es en esto equiparable, el intercambio sigue el principio de la justicia conmutativa y se muestra como fundamental

Según el argumento del intercambio trascendental, los derechos humanos y los deberes humanos no caen del cielo y luego requieren de su reconocimiento recíproco. Tampoco son válidos porque conformen el consenso básico de las democracias liberales, ni tampoco, por último, porque se acrediten como respuestas a las dificultades de las comunidades preliberales. Ello más bien lo logra la mencionada conditio humana socialis, la posibilidad de ser tanto víctima como agente de la violencia, de domeñarla de una manera universalmente digna de aprobación. 


\subsection{Libertad de opinión y religión.}

Las "acciones" son sucesos que no transcurren de manera reflexiva, ni instintiva, sino más bien intencional; por eso están ligados a la capacidad de pensamiento y habla. Incluso si identificáramos una especie no humana como capaz de acción, tendría que disponer de capacidad de pensamiento y habla. Para la segunda determinación (trascendental-)antropológica resulta ajustada una reflexión análoga a la del primer derecho humano. En el aspecto práctico, aqui decisivo, la capacidad de pensamiento y habla está concebida en un sentido amplio: que los intereses habituales no existen porque sí, sino que más bien se configuran esencialmente en la reflexión y en el pensar y en el hablar con los otros. De esta manera reflexiva y comunicativa, discursiva incluso en el caso de los debates sobre los fundamentos, adquieren su perfil más nítido las ideas tanto sobre los fines del deseo, como sobre los medios para su realización y, no en último lugar, las opiniones relativas al mundo social y natural. (En el marco de la capacidad de pensamiento y habla tienen su lugar la religión y también, de otro modo, los medios de comunicación).

Los fines y los medios pueden resultar ciertamente diferentes, pero dado que presuponen la capacidad de pensamiento y habla, se les erige enfrente un interés superior, incluso trascendental. Toda persona tiene el interés, en el pensar y en el hablar con los otros, de poder desarrollar sus opiniones relativas a la acción de tal manera que pueda conformar y perseguir sus intereses habituales. Obviamente para ello no es necesario un completo desarrollo de la capacidad de pensamiento y habla, pero sí un mínimo determinado. El intercambio trascendental negativo necesario para ello amplia la renuncia a la violencia.

Sólo a través de la renuncia recíproca a impedir las opiniones de los otros (incluidas las representaciones religiosas de la fe), surge aquel derecho a la libertad de opinión (incluida la libertad de credo y de conciencia, la libertad científica y artística, la libertad de prensa, etc.) que medio posibilita el lado intencional de la capacidad humana de acción en general, medio lo lleva a su desarrollo. De forma análoga a la integridad del cuerpo y vida, puede hablarse aquí de la integridad de la capacidad de pensamiento y habla, y diferenciarla como integridad lógica y comunicativa de la habitual integridad biológica y física: al derecho humano a estar libre de la violencia de los otros le corresponde de nuevo la obligación humana de renunciar por su parte al uso de la violencia. De la renuncia procede asimismo una prestación positiva, la integridad lógica y comunicativa, sin la que no existiría ningún interés por el intercambio. Finalmente, cada cual da y recibe lo mismo, de tal modo que el intercambio de nuevo resulta justo en un sentido fundamental.

\subsection{Derechos de libertad positiva, derechos sociales.}

El renunciar a la violencia todavía no posibilita por sí solo la capacidad de actuar. Tanto la vida como el desarrollo del habla o el raciocinio precisan 
prestaciones positivas que atañen por un lado al talento y por otro al esfuerzo, a la posición social y a las oportunidades brindadas por la fortuna. El hecho de que el ser humano sea tan menesteroso como capaz de tales prestaciones positivas viene a constituir su naturaleza social. Para difuminar la capacidad de suponer una amenaza recíproca, se habla más exactamente de una naturaleza social positiva o de un talante cooperativo en contraposición a la naturaleza social destructiva, el conflicto y la violencia.

Con las reivindicaciones que se aplican a la polifacética naturaleza social algunos proceden de manera auténticamente generosa. Confeccionan copiosas listas de derechos sociales, acometiendo su legitimación sin circunscribirse previamente a los deberes abstractos de la solidaridad y la filantropía. Lo acreditado en la política puede no remediar el déficit para fundamentar una invocación a la justicia social que sea tendencialmente inflacionaria. Pues a diferencia de otras nociones de justicia: la conmutativa, la distributiva, la compensatoria e incluso la procesual, el concepto de justicia social es muy reciente y todavía no ha encontrado una justificación convincente. Con todo, merced a su filiación en la ética social del cristianismo, corre el riesgo de verse demasiado aparejada con una solidaridad de inspiración cristiana.

La falta de fundamentación de que adolecen hasta el momento los derechos sociales puede aplicarse a su significado para la capacidad de actuar. Por ello los derechos sociales se agregan prácticamente sin costuras a los derechos de la libertad negativa. En la medida en que sean funcionalmente relevantes para la libertad no poseen menor cualificación como derechos humanos que los derechos concernientes a la libertad negativa. Estos aparecen como prioritarios en cuanto que lo son actualmente para un "sujeto renuente a la cooperación", para unos anacoretas en sentido estricto; incluso quien destierra cualquier cooperación por su parte quiere hallarse seguro ante la violencia del otro. En tanto que los derechos de libertad negativa son indiferentes a la cooperación, los derechos de libertad positiva se muestran en cambio dependientes de la cooperación. Sin embargo, una conducta renuente a la cooperación queda en entredicho para cualquiera que no haya logrado disfrutar previamente durante algún tiempo de los más elementales derechos sociales, cual son los derechos a la nutrición y a la vestimenta, así como a una cierta educación.

La propia expresión derechos de libertad "positiva" anuncia que, sin duda, se distingue esencialmente de los derechos de libertad "negativa". Los primeros no se corresponden ya con resultados negativos o renuncias, sino con prestaciones positivas como por ejemplo las cuitas en lo tocante a alimentación, vestido y vivienda, la salud, la formación y la educación. Más allá de todo esto el hombre busca también una seguridad y un reconocimiento, pero esto es algo que difícilmente puede ser encajado bajo la forma de unos derechos sociales reivindicables. En cuanto derechos de prestación los derechos para la libertad positiva constituyen un problema que desconocen los derechos profilácticos: el hallarse supeditados a la falta de medios. 
De esta diferencia se deriva una segunda. Mientras que los derechos a la libertad negativa pueden verse reclamados bajo cualesquiera circunstancias, incluida la falta de medios, esto es algo que le está vetado a los derechos sociales. Exceptuando la legítima defensa quien mata a otro vulnera siempre un derecho humano. En cambio, quien deja que alguien muera de inanición o de frío porque no puede suministrar el alimento y la ropa necesarios no se hace culpable de quebrantar derecho humano alguno.

En esa segunda diferencia se indica la tercera. Los resultados positivos son esencialmente comparativos; hay un más y un menos a los que ha de acomodarse la determinación tanto de los recursos existentes como de las necesidades de una sociedad; los derechos sociales dependen tanto de los recursos como del marco cultural. Así por ejemplo, en las zonas frías se precisan ropas y hogares de más abrigo que en las cálidas. Y la exigencia de "unas vacaciones periódicas remuneradas" (art. 24 de la Declaración Universal de los Derechos Humanos) para un trabajo corporal o intelectualmente extenuante tendrá difícil cabida en un modo de trabajar que ya entrañe de suyo los elementos del descanso. En las culturas anteriores a la escritura nadie sabía leer y escribir, siendo muy pocos quienes saben hacerlo en aquellas culturas donde la escritura es de reciente aparición, de tal manera que la alfabetización no supone un ingrediente cultural para el reconocimiento de los derechos humanos. Por contra en las sociedades altamente especializadas se requiere mucho más que ser capaces de leer y escribir; para satisfacer determinadas opciones vitales se hace irrenunciable tener acceso a una educación tan amplia como especializada.

Según se ha señalado, en ciertos entramados sociales un derecho a la formación y a la educación puede alcanzar el rango de un derecho humano. $Y$ allí donde uno tiene que procurarse los medios de subsistencia mediante el trabajo, resultando éste decisivo tanto para la propia estima como para el respeto hacia los otros, además de contribuir al desarrollo de la personalidad, no carece de sentido que el derecho al trabajo sea un derecho humano. Aun cuando pueda entrar en colisión con un derecho de libertad negativa, cual es la libre elección de una profesión. Además siempre está ahî el problema de los recursos: los puestos de trabajo pueden resultar escasos coyuntural o incluso estructuralmente. No por citarlas al final son menos relevantes las condiciones personales previas, cual son los requisitos relativos a la cualificación y la predisposición al trabajo individual o en equipo.

Las condiciones personales previas juegan también un papel en otro terreno, como por ejemplo la aptitud y la aplicación en el estudio o la predisposición a ahorrar llegado el caso en materia de recursos materiales mediante una restricción del consumo. De aquí se deduce una cuarta diferencia. Los derechos para la libertad positiva son algo más que simples "deseos piadosos" o "ufanas promesas", pero sí son algo menos que derechos individuales subjetivamente reclamables. Antes bien se trata de exigencias programáticas para cuya transformación se precisan complejas apreciaciones en la realidad social. Y dichos 
juicios pueden verse políticamente cuestionados tanto por el marco general de los derechos sociales como asimismo por las distintas evaluaciones de las legalidades económicas y sus eventuales contextos.

Una quinta particularidad: los rendimientos citados no han de ser conseguidos por todos los hombres. Tan pronto como un individuo rehúsa renunciar a la violencia frente a otro, su cuerpo y su vida quedan eo ipso expuestos al peligro. El renunciar a la violencia no debe circunscribirse en modo alguno al círculo de "mis allegados y amigos". En cambio si alguien deniega las prestaciones indicadas, otros podrán sustituirle sin problemas. Pero de ahí no se sigue que los derechos sociales sean, como se teme en muchas ocasiones, pretensiones confusas o incluso tan sólo un manifiesto jurídico de índole retórica.

El hecho mismo de que las prestaciones no hayan de ser conseguidas por todos plantea sin duda la cuestión añadida de a quién le corresponde aportarlas. A lo cual se responde -sexta diferencia- con el "productor natural de prestaciones". Pues sólo quien ayuda al indigente sin ser culpable de su indigencia actúa por beneficencia. En cambio quien ha coadyuvado a esa indigencia soporta según el grado de su complicidad una responsabilidad en la justicia compensatoria (correctiva). Así se hallan por ejemplo comprometidos los padres para con sus hijos, pues ellos los han traído al mundo sin su consentimiento como seres menesterosos de auxilio.

Pese a sus diferencias los derechos para la libertad positiva coinciden con los derechos de libertad negativa en el modelo de legitimación: el intercambio transcendental. Ciertas donaciones son tan elementales que resultan irrenunciables, en parte por mera supervivencia, en parte por una capacidad de actuar autorresponsablemente. Porque las donaciones que resultan asimétricas, donde quienes son capaces de ello prestan ayuda a los que se hallan necesitados de auxilio, parecen adolecer de la segunda condición de la legitimación: la reciprocidad. Mas esto cambia cuando se toman en cuenta un cambio de fases; los niños pueden "reparar" la ayuda que reciben mediante aquella ayuda que presten de mayores acaso también a sus entonces desvalidos padres.

Aunque a los derechos de libertad positiva también les corresponda teóricamente un momento de intercambio, éste no basta para la legitimación. También desde un punto de vista legitimatorio los derechos a la libertad positiva se muestran entonces más complejos que los derechos a la libertad negativa, lo cual hace comprensible que hasta el momento carezca de una justificación adecuada. Las prestaciones a intercambiar cuentan con el presupuesto de que no se deben a un trueque ni a otra prestación humana. El último fundamento de cualquier trabajo es que cuanto menos esfuerzo conlleva resulta mucho más ventajoso: nuestro planeta cuenta con sus riquezas del subsuelo, frutos y animales tanto del cielo como de la tierra y el agua. Ahora bien, en el territorio donde tales recursos escasean se plantea una primordial tarea distributiva que invita a planificar un tercer tipo de justicia, la distributiva, con arreglo a la justicia conmutativa y a la equitativa. Observaremos entre paréntesis 
que para la justicia de un ordenamiento patrimonial esos tres tipos de justicia desempeñan un papel y que en la justicia distributiva cuenta tanto el punto de vista de la libertad negativa como el de la positiva. Todas las teorías acerca de la propiedad acometen por ello una inadmisible simplificación al desatender cuando menos cuatro principios de la justicia: el derecho a la libertad negativa y positiva sobre la propiedad, el precepto de compensar pasadas injusticias y una primordial justicia distributiva.

\section{Seis modernizaciones del Estado nacional}

Tras esta somera fundamentación podemos retornar a aquella presión de tener que justificarse al que están sometidos hoy en día los Estados nacionales. A la vista de los derechos humanos universales y la necesidad de actuar globalmente no puede seguir dándose bajo una configuración nacionalista que no sea agresiva. La configuración legítima actualmente y con perspectivas de serlo en el futuro es el "Estado nacional ilustrado", que se caracteriza por seis modernizaciones.

Conforme a una primera modernización bajo la compleja expresión histórico-conceptual de "nación" se comprende primariamente la civitas, esto es, los ciudadanos, y no la gens: esa estirpe con antepasados comunes a los que Aristóteles otorgó la hermosa metáfora del homogalaktes, los camaradas de leche. La nación de ciudadanos cuenta con una clara primacía sobre la nación basada en el linaje y es que la versión nacionalista (j"salvése la etnia”!) no está en tela de juicio. En su lugar todos los ciudadanos del Estado son jurídica y políticamente iguales al margen de su pertenencia étnica. Uno se libera al mismo tiempo del ensalzamiento de la propia comunidad y de la devaluación, cuando no agresiva impugnación, de la comunidad ajena, que tan a menudo arranca desde los mitos fundacionales y cuyo modelo es la célebre Eneida de Virgilio: mediante la imaginada conjunción de la historia romana con la mitología se venía a justificar la pretensión romana de constituir una potencia mundial. Ni lo propio ha de ser mejor que lo ajeno, ni la comunidad solidaria se corresponde necesariamente con el reverso interno del anverso externo de la comunidad beligerante que se abandona a la dialéctica entre amigos y enemigos.

El sociólogo británico Gellner cree que, en relación al ordenamiento político, la historia mundial podría dividirse en tres épocas: el período de las tribus nómadas de recolectores y cazadores, la época de las sociedades agrícolas con jerarquías estables y pueblos diversos, y la era de las sociedades industrializadas compuestas por Estados nacionales. Un simple vistazo a la antigüedad y más allá de las fronteras europeas nos previenen contra este esquema. China, Corea y Japón perdieron su carácter poliétnico mucho antes de la industrialización. Las ciudades-repúblicas griegas no admiten ser consideradas simples sociedades agrícolas en términos económicos ni tampoco un consorcio de pueblos desde 
un punto de vista político. Bien al contrario su identidad colectiva no se diferencia radicalmente de una comunidad nacional. Según Herótodo ésta se define mediante seis rasgos comunitarios: por el linaje, la lengua y la religión, así como por la forma de vida, el territorio y la unidad política. En cambio Egipto se aisló ya desde la época del bronce (2800-2650 a.C.) y eliminó la influencia de otros pueblos, sin que uno pueda adoptar problemáticamente los criterios de Heródoto. Pues los dialectos del antiguo egipcio son acuñados con tanta viveza que dificultan la reconciliación interlocal; y la forma de vida es sólo común para las castas superiores.

Tampoco en la modernidad se define la homogeneidad "nacional" mediante esos mismos elementos. Así por ejemplo, para Polonia el compartir un credo religioso juega un papel tan importante como el tener una lengua común, mientras que Bélgica reúne a distintas culturas lingüísticas como la flamenca, la valona y la alemana. Por contra Alemania y Suiza se configuran por encima de las diferencias religiosas; y en los Estados Unidos de Norteamérica una mayor diversidad religiosa logra constituir grandes dosis de tolerancia en la comunidad. De estas observaciones viene a colegirse algo para la semántica de lo nacional y es que no hay un núcleo esencial ni un ideal al cual uno haya de aproximarse; antes bien existe un aire de familia en sentido wittgensteiniano.

Hay Estados étnicamente homogéneos como China (con un noventa y dos por ciento de la población), Corea y Japón, aparte de algunos países escandinavos como particularmente Suecia y todavía más Islandia. Desde su colonización hace miles de años por los vikingos Islandia se ha mezclado poco con otros pueblos, de tal modo que la población está constituida casi exclusivamente por islandeses en sentido étnico. Sin embargo, difícilmente se considerara que tal Estado denota un "alto grado de nacionalismo" que le acerca al ideal del Estado nación y en el platillo opuesto se rebaje a los poliétnicos Estados Unidos de Norteamérica hasta considerarlo un estado de "débilmente nacionalista". Conforme a los que vamos viendo aquí la configuración de una nación se debe a otros factores como son la constitución y el derecho.

En la antigüedad prevalecía la exclusividad, tal como se evidencia en la historia del cortesano egipcio Sinué (hácia el siglo XVIII a.C.): quien había nacido egipcio permanecía todo su vida como tal y, si por casualidad salía al extranjero, retornaba luego a Egipto para morir. Tras la segunda modernización se depone tal exclusividad (de ser para siempre egipcio o griego). $\mathrm{Ni}$ se prohíbe un cambio individual de nacionalidad, así como tampoco se veta una transformación colectiva mediante un nuevo reagrupamiento estatal que de lugar a unidades menores o mayores. Los Estados nacionales ilustrados no tienen por algo sacrosanto ni la procedencia nacional del individuo ni las colectivas configuraciones estatales dadas. $\mathrm{Y}$ bajo ciertas condiciones hacen concebible una doble nacionalidad sin sustraerse a sus dificultades. Pues la ilustración toma en cuenta ambas vertientes, es decir, considera tanto las ventajas como los riesgos. 
De la nacionalidad dependen importantes derechos y deberes de prestaciones por parte del Estado, tales como el servicio militar o la prestación sustitutoria y las garantía legales frente a otros Estados. Pues en ciertos lugares añaden a los derechos de cogestión política fueros especiales con respecto a "propiedades sensibles" como el patrimonio inmobiliario y las obras de arte, comportando la doble nacionalidad una ventaja que contradice el principio jurídico-democrático de la igualdad y sólo resulta legítimo en casos excepcionales. Esta ventaja empieza en los dobles derechos de cogestión y prosigue en el doble privilegio nacional de la competencia patrimonial. Ante la limitada capacidad de prestaciones por parte de los individuos se pone de manifiesto la ventaja implícita en que un Estado comparta sus prestaciones, tales como la del servicio militar o el servicio social sustitutorio, con algún otro Estado, aun cuando dicha prestación tenga que ampliar la protección jurídica.

Particularmente problemático resulta si en el servicio militar a uno le cabe decidir sobre los derechos humanos del Estado agresor. Con arreglo a una tercera modernización al Estado nacional ilustrado le enorgullece su reconocimiento de los principios universales relativos a la justicia, es decir, de los derechos humanos. Esta evidente supremacía se revela para la ciudadanía en cosas tales como la transparencia del "mundo de vida político" para con las minorías. Con una nación poliétnica el Estado nacional ilustrado no tiene dificultades en materia de principios. Así y todo la globalización impone transparencia. Y con carácter previo hay «elementos comunes que traspasan las fronteras estatales» como el lenguaje y la religión, la edad, el género, la profesión y el trabajo. Estos factores transnacionales relativizan las fronteras políticas, encargándose de que una nación homogénea y unificada conforme al linaje y la religión, así como también por el modo de vida y las costumbres, suponga una excepción. De ahí no se sigue desde luego que los Estados ilustrados se dejen reducir a un patriotismo constitucional. Pues todavía se dan otros factores muy relevantes para su conciencia estatal, en el caso de los Estados Unidos de Norteamérica la lengua común, una conciencia misionera (God's own country), incluso «deportes específicamente territoriales» como el béisbol y el fútbol, aparte de experiencias compartidas como la del Go West para la conquista y el cultivo de los territorios, o el no menos importante e intenso optimismo por el futuro del American dream.

El hecho de que el lenguaje juegue su papel junto al derecho y la constitución está ligado con la democracia y es propio de la cuarta modernización. Cuanto más por encima del patriotismo constitucional se sitúa un Estado nacional tanto más integra las particularidades que sirven a la nación de ciudadanos. Y estos elementos "cívico-funcionales" fortalecen la supremacía de la nación de ciudadanos sobre la nación étnica. Hay ciertos elementos que para la nación de ciudadanos no son altruistas o caritativos, sino sencillamente irrenunciables; dichos elementos tienen el rango de universalismos particulares. Son universales porque cualquier ciudadanía los precisa, y son particulares porque cobran mayor o menor cuerpo en una hechura idiosincrática. El Estado nacional ilustrado 
conjuga, por lo tanto, "universalismos universales", como los derechos humanos y la democracia, con "universalismos particulares", entre los cuales el lenguaje posee una eminente significación. Incluso se dan obligaciones jurídicas no escritas que son recopiladas oralmente, viéndose administradas e interpretadas por un lenguaje determinado. Existen lenguajes administrativos y judiciales muy bien definidos. En la civilización altamente desarrollada sobre la estatalidad, la democracia participativa comparece el incesante debate del intercambio de argumentos, visiones y experiencias. $\mathrm{Y}$ las obligaciones resultantes son deliberadas y decididas en sede parlamentaria, tras haber sido comentadas por los partidos y la opinión pública. (Por esta razón Francia no se define únicamente mediante sus tres principios universales de liberté, egalité et fraternité, sino también por medio de un cuarto, un principio particularista, que podría denominarse françaiseté: por la lengua y la cultura francesas).

En cuanto comunidad de discurso la democracia supone una comunidad de habla; y la lengua es tan elemental como vital es el agua para los peces o el aire para los pájaros. Sin embargo, el lenguaje no ha de presentarse nunca en singular. También un plurilingüismo bien asentado crea una comunidad lingüistica, ahora en un segundo nivel cuando alguien que no conoce éste u otro lenguaje lo aprende en la escuela como medio para la polémica. Ni Bélgica, ni Finlandia, India, Canadá o Suiza desentonan con el tipo del "Estado nacional" democrático; su plurilingüismo contribuye más bien al perfil particular. Ciertamente, en singular o en plural -como cualquier factor de individualización el idioma predominante también se ha desarrollado históricamente y pese a todo se ha tenido que ver fortalecido por una voluntad política, incluso en un plebiscito cotidiano tal como indica la célebre conferencia de Renan titulada Qu'est-ce qu'une nation? (1882). La voluntad puede disminuir o pulverizar una voluntad opuesta. Pero ninguna comunidad debería no mostrarse apta y preparada para el plurilingüismo, sino mostrarse abierta a todas las lenguas de este mundo sin comprometerse con una en particular.

Aquello que los Estados nunca han sido por mor del entrecruzamiento político de las comunidades, tiene aún menor cabida en la era de la globalización: no son comunidades autárquicas que existan cual mónadas perfectas e independientes las unas de las otras. Tras las dos últimas modernizaciones el Estado nacional reacciona constructivamente ante ellas. Por un lado, no considera la globalización como un motivo de angustioso resentimiento. Conforme a una quinta modernización encara más bien las novedades como una oportunidad para la innovación. En el marco de la globalización también hay lugar para una competencia política y las comunidades han de interiorizar que son capaces de aprender, tanto a abandonar estructuras como también a cambiar mentalidades. Y aquí se plantea la cuestión de si, compitiendo con Estados que son aliados políticos, Alemania puede vanagloriarse de estar a la cabeza de la innovación política. La sexta modernización consiste finalmente en una triple apertura. En primer lugar la apertura hacia las nuevas creaciones macrorregionales, a comunidades política como la Unión Europea, las cuales resuelven 
ya la mayor parte de los problemas "en la propia casa". En segundo lugar la apertura hacia un orden global mundial y, en tercer lugar, hacia la justicia para con las futuras generaciones.

Antes de definir un poco más la apertura intermedia, puede hacerse un balance provisional: suponiendo que el Estado nacional se someta a esta séxtuple ilustración, no se manifiestan razones empíricas o legitimatorias que se le antojen anacrónicas. $\mathrm{O}$ bien se ve arrastrado por las fuerzas globalizadoras, o bien se ve deslegitimado por la necesidad de actuar globalmente, quedando claramente relativizado bajo cualquiera de ambas perspectivas. Las sociedades contemporáneas pueden comprenderse como "postnacionales" al responder a esta pregunta: ¿Dónde encuentra su lugar Alemania, al margen de esa comunidad donde no recientemente, sino ya en tiempos de Kant, uno "no se apega apasionadamente a su patria"? (Antropología en sentido pragmático; $2^{\mathrm{a}}$ Parte, $C, 5)$. Una obligación moral no se perfila muy bien a partir de esta autocomprensión; "nacionalmente ilustrada" sigue siendo una alternativa legítima. Pero, ¿cómo se aviene esto con un ordenamiento político-jurídico de carácter global?

Obviamente la necesidad de actuar globalmente sólo puede llevarse a cabo limitando las estructuras tradicionales de los Estados soberanos nacionales. Incluso los instrumentos de la diplomacia y el derecho internacional clásicos, así como las alianzas interestatales y la red entre organizaciones supranacionales que constituian hasta la fecha el orden mundial, las Naciones Unidas, se muestran tan meritorias como insuficientes a la postre. El neoliberalismo quiere confiar por completo a las fuerzas del mercado el desenlace de la tarea global. Sin duda, el "libre juego de las fuerzas", sometidas ciertamente a una ruda competencia, contribuye a la riqueza de la humanidad; no sólo a la riqueza de bienes y servicios, sino también al enriquecimiento de la ciencia, la técnica, la música, la literatura y el arte. Por consiguiente, sería insensato dar un giro en sentido opuesto hacia un "estatalismo" que pretendiera solventar todos los problemas desde el gobierno del Estado merced a un intervencionismo impuesto por arriba. De este modo se gestionaría la riqueza (jno sólo económica!), pero se precisa de marcos vinculantes: un ordenamiento jurídico orientado hacia la paz. Para asumir problemas globales tiene que darse un carácter igualmente global. Y si la polifacética globalización no debe saldarse con una regresión política, entonces el ordenamiento jurídico y la paz globales han de someterse a las mismas condiciones que toda sociedad particular: la democracia liberal, social y participativa. Por lo tanto se requiere que se dé una democracia mundial: una república mundial.

Por otro lado, no debe dejarse de fomentar el Estado particular. Muchos problemas se solventan todavía a ese nivel político y nuestro destino se ventila regional, municipal e individualmente. De ahí que una república mundial no pueda ocupar el lugar de los Estados particulares y sus ricas ramificaciones regionales o municipales. Posee más bien un rango auxiliar (subsidiario) y adicional (complementario). Sin duda es edificado "desde abajo", por los ciu- 
dadanos y las comunidades ya existentes. Y cede un derecho ante el Estado particular al tener un carácter federal. Por eso, para erigir una democracia mundial con un ordenamiento jurídico y de paz a escala universal como una liga mundial de Estados, como una república mundial subsidiaria y federal. Ésta no surge "de un solo golpe", sino más bien al calor de la disputa, como una concentración progresiva de las redes y organizaciones supra- e internacionales ya existentes, y en donde un tribunal internacional lograria introducir notables progresos. Al mismo tiempo la humanidad ha de originar una nación, esto es, una carta de ciudadanía que comience con un núcleo de justicia y comparta mutuamente valores elementales. No ha de esperarse, sin embargo, una nación convencional. En modo alguno la humanidad debe renunciar a su riqueza, a su divergencia lingüística, cultural, religiosa y social. Por eso la república mundial deja en su lugar, en cuanto unidad federal y subsidiaria, a las naciones primarias sus propias peculiaridades y sus propios derechos. Se contenta con el rango de constituir una nación secundaria y, si se da un sentido más amplio al modelo de la Unión Europea, incluso sólo terciaria -con un exiguo carácter "nacional". Al final, en un futuro que esperemos no sea demasiado lejano, se poseerá una triple ciudadanía. Primariamente uno será alemán, francés, italiano o español; en segundo lugar será ciudadano europeo (o latinoamericano, africano, etc.); y en tercer lugar cosmopolita: ciudadano de la subsidiaria y federal república del mundo.

\section{BIBLIOGRAFÍA}

Böckentförde, E.-W. y Spaemann, R. (eds.) [1987]: Menschenrechte und Menschenwürde, Stuttgart.

Emacora, F. (1983): Menschenrechte in der sich wandelnden Welt (vol. II: Theorie und Praxis. Die Verwirklichung der Menschenrechte im Nahen Osten), Viena.

Gauchet, M. (1989): La Révolution des Droits de l'Homme, París.

Höffe, Otfried (1987): Politische Gerechtigkeit, Suhrkamp, Francfort.

- (1992): "Ein transzendentaler Tausch: Zur Anthropologie der Menschenrechte", en Philosophisches Jahrbuch 99, pp.1-28.

- (1998): Vernunft und Recht. Bausteine zu einem interkulturellen Rechtsdiskurs, Suhrkamp, Francfort.

- (1999): Gibt es ein interkulturelles Strafrecht?, Surhkamp, Francfort.

- (1999a): Demokratie im Zeitalter der Globalisierung, Beck, Munich.

: Kleinheyer, G. (1975): "Grundrechte", en Brunner, O./W. Conze/R. Koselleck (eds.), Geschichtliche Grundbegriffe, vol. 2, pp. 1047-1082, Stuttgart.

Vierhaus, R. (ed.) [1977]: Herrschaftsverträge, Wahlkapitulationen, Fundamentalgesetze, Gotinga. 